\title{
Microstructure and Mechanical Properties Evolution during Solution and Ageing Treatment for a Hot Deformed, above $\beta$-transus, Ti-6246 Alloy
}

\author{
Mohammed Hayder Ismail Alluaibi ${ }^{1}{ }^{\circledR}$, Elisabeta Mirela Cojocaru ${ }^{1}$, Adrian Rusea ${ }^{2}$, \\ Nicolae Șerban ${ }^{1}$ (D), George Coman ${ }^{1}$ and Vasile Danut Cojocaru ${ }^{1, *(D)}$ \\ 1 Materials Science and Engineering Faculty, University Politehnica of Bucharest, 060042 Bucharest, Romania; \\ mohammed.aluaibi@gmail.com (M.H.I.A.); mirela.cojocaru@mdef.pub.ro (E.M.C.); \\ nicolae.serban@upb.ro (N.Ș.); george.coman@upb.ro (G.C.) \\ 2 SC ZIROM SA Giurgiu, 080331 Giurgiu, Romania; adrian.rusea@zirom-titanium.com \\ * Correspondence: dan.cojocaru@upb.ro; Tel.: +40-21-402-9531; Fax: +40-21-316-9562
}

Received: 26 July 2020; Accepted: 17 August 2020; Published: 19 August 2020

check for updates

\begin{abstract}
The present study investigates the influence of hot-deformation, above $\beta$-transus and different thermal treatments on the microstructural and mechanical behaviour of a commercially available Ti-6246 titanium-based alloy, by SEM (scanning electron microscopy), tensile and microhardness testing techniques. The as-received Ti-6246 alloy was hot-deformed-HR by rolling, at $1000{ }^{\circ} \mathrm{C}$, with a total thickness reduction (total deformation degree) of $65 \%$, in 4 rolling passes. After $\mathrm{HR}$, different thermal (solution-ST and ageing-A) treatments were applied in order to induce changes in the alloy's microstructure and mechanical behaviour. The applied solution treatments (ST) were performed at temperatures below and above $\beta$-transus $\left(\alpha \rightarrow \beta\right.$ transition temperature; approx. $\left.935^{\circ} \mathrm{C}\right)$, to $800^{\circ} \mathrm{C}, 900^{\circ} \mathrm{C}$ and $1000{ }^{\circ} \mathrm{C}$ respectively, while ageing treatment at a fixed temperature of $600{ }^{\circ} \mathrm{C}$. The STs duration was fixed at $27 \mathrm{~min}$ while A duration at $6 \mathrm{~h}$. Microstructural characteristics of all thermomechanical (TM) processed samples and obtained mechanical properties were analysed and correlated with the TM processing conditions. The microstructure analysis shows that the applied TM processing route influences the morphology of the alloy's constituent phases. The initial AR microstructure shows typical Widmanstätten/basket-weave-type grains which, after HR, are heavily deformed along the rolling direction. The STs induced the regeneration of $\alpha$-Ti and $\beta$-Ti phases, as thin alternate lamellae/plate-like structures, showing preferred spatial orientation. Also, the STs induced the formation of $\alpha^{\prime}-\mathrm{Ti} / \alpha^{\prime \prime}-\mathrm{Ti}$ martensite phases within parent $\alpha$-Ti $/ \beta$-Ti phases. The ageing treatment (A) induces reversion of $\alpha^{\prime}$-Ti $/ \alpha^{\prime \prime}$-Ti martensite phases in parent $\alpha$-Ti/ $\beta$-Ti phases. Mechanical behaviour showed that both strength and ductility properties are influenced, also, by applied TM processing route, optimum properties being obtained for a ST temperature of $900{ }^{\circ} \mathrm{C}$ followed by ageing (ST2 + A state), when both strength and ductility properties are at their maximum $\left(\sigma_{\text {UTS }}=1279 \pm 15 \mathrm{MPa}\right.$, $\left.\sigma_{0.2}=1161 \pm 14 \mathrm{MPa}, \varepsilon_{f}=10.1 \pm 1.3 \%\right)$.
\end{abstract}

Keywords: titanium-based alloys; $\alpha+\beta$-Ti alloy; microstructure; mechanical properties

\section{Introduction}

In the past decades, the demand for structural materials possessing high strength, high plasticity and high corrosion resistance increased due to the rapid development in modern industries, where such combination of properties is demanded, i.e., automotive and aeronautical industry [1-7]. Titanium alloys proved that they can satisfy all imposed demands if an appropriate thermomechanical processing route is applied [1-7]. 
Usually, titanium alloys can be classified according to their component phases in: $\alpha$-class alloys, possessing a mono-phase microstructure consisting of $\alpha$-Ti phase (belonging to hexagonal close-packed-HCP crystalline system) such as: CP-Ti Grade 1 to CP-Ti Grade $4, \beta$-class alloys, possessing a mono-phase microstructure consisting of $\beta$-Ti phase (belonging to body-centred cubic- $\mathrm{BCC}$ crystalline system) such as: Ti-15Mo, Ti-13Nb-13Zr, Ti-11Nb-7Fe, near $\alpha$-class and near $\beta$-class alloys, which besides the main $\alpha$-Ti/ $\beta$-Ti phase are possessing small/traces quantities of $\beta$-Ti $/ \alpha-\mathrm{Ti}$ phase and, $(\alpha+\beta)$-class alloys-possessing a dual-phase $\alpha$-Ti/ $\beta$-Ti microstructure such as: Ti-6Al-4V (Ti-64), Ti-6Al-7Nb (Ti-67), Ti-5Al-2.5Fe (Ti-52.5), Ti-7Al-4Mo (Ti-74), Ti-6Al-2Sn-4Zr-6Mo (Ti-6246) and Ti-based shape-memory alloys [7].

The $\alpha$-class alloys showed high strength but limited ductility and corrosion resistance while the $\beta$-class alloys showed higher ductility and corrosion resistance but lower strength [7]. The $(\alpha+\beta)$-class Ti alloys showed an excellent combination of strength/ductility and corrosion resistance properties in comparison with $\alpha$ and $\beta$ classes [8,9]. The Ti-based shape-memory alloys, especially those belonging to Ti-Ni system, possess an interesting combination of strength, superalesticity and shape memory effects, properties which are largely influenced by the alloying elements [10].

In the case of $(\alpha+\beta)$-class alloys the exhibited mechanical behaviour can be stirred towards increased strength or ductility by manipulating the weight-fraction balance between the $\alpha-\mathrm{Ti} / \beta-\mathrm{Ti}$ phases. If the weight-fraction of $\alpha$-Ti phase is increased than the exhibited mechanical properties are directed towards increased strength $[10,11]$. If the weight-fraction of $\beta$-Ti phase is increased the exhibited mechanical properties are directed towards increased ductility [11,12].

The morphology, grain size and weight-fraction ratio of the $\alpha$-Ti/ $\beta$-Ti phases are influenced by the specific parameters of the applied thermomechanical processing route and, hence, have a direct influence on alloy's exhibited mechanical behaviour $[13,14]$. Generally, in order to manipulate alloy's exhibited properties a solution treatment is performed, at a temperature below or above $\beta$-transus $(\alpha-\mathrm{Ti} \rightarrow \beta$-Ti transformation/transition temperature) and rapidly cooled, in order to induce formation of $\alpha^{\prime}$-Ti and/or $\alpha^{\prime \prime}$-Ti phases, which can increase/decrease strength, ductility, hardness and corrosion resistance properties $[15,16]$. The $\alpha^{\prime}$-Ti martensitic phase shows an HCP crystallographic structure, similar with the parent $\alpha$-Ti phase, but with small differences in crystal lattice parameters. The $\alpha^{\prime \prime}$-Ti martensitic phase has an orthorhombic crystallographic structure and very different lattice parameters when comparing with parent $\beta$-Ti phase [17-19]. When high ductility is envisaged, the applied thermomechanical processing assumes a final ageing treatment, aimed to partially/totally revert the $\alpha^{\prime}$-Ti $/ \alpha^{\prime \prime}$-Ti phases into the parent $\alpha$-Ti/ $\beta$-Ti phases [16] and thereby, the exhibited mechanical behaviour can be adjusted as needed [20-25].

Considering the demand for an adequate combination of strength and ductility properties it is important to study the influence of different thermomechanical processing conditions on alloy's microstructure evolution and exhibited mechanical behaviour [26-30]. The present work aims, first, to study the influence of solution treatments performed at temperatures below and above $\beta$-transus $\left(800{ }^{\circ} \mathrm{C}, 900{ }^{\circ} \mathrm{C}\right.$ and $\left.1000{ }^{\circ} \mathrm{C}\right)$ and, second, the influence of an ageing treatment performed $\left(600{ }^{\circ} \mathrm{C}, 6 \mathrm{~h}\right.$, air quenching) on microstructure evolution and exhibited mechanical behaviour of Ti-6246 alloy.

\section{Materials and Methods}

The investigated Ti-6246 alloy was industrially produced by Vacuum Arc Remelting (VAR) at S.C. ZIROM TITANIUM S.A. (Giurgiu, Romania), using a double VAR processing route. From the $\varnothing 600 \mathrm{~mm}$ ingots (as-received AR state) samples were cut and thermo-mechanically (TM) processed according to the processing route presented in Figure 1. The as-received (AR) Ti-6246 alloy was hot deformed by rolling (hot-rolled-HR), at a temperature of $1000{ }^{\circ} \mathrm{C}$, in 4 rolling steps with 3 intermediary reheating stages, to a total thickness reduction (deformation degree) of approximately $\varepsilon_{\text {total }} \approx 65 \%$. For each rolling step, a constant deformation degree $\left(\varepsilon_{\text {partial }} \approx 16 \%\right)$ was used. 


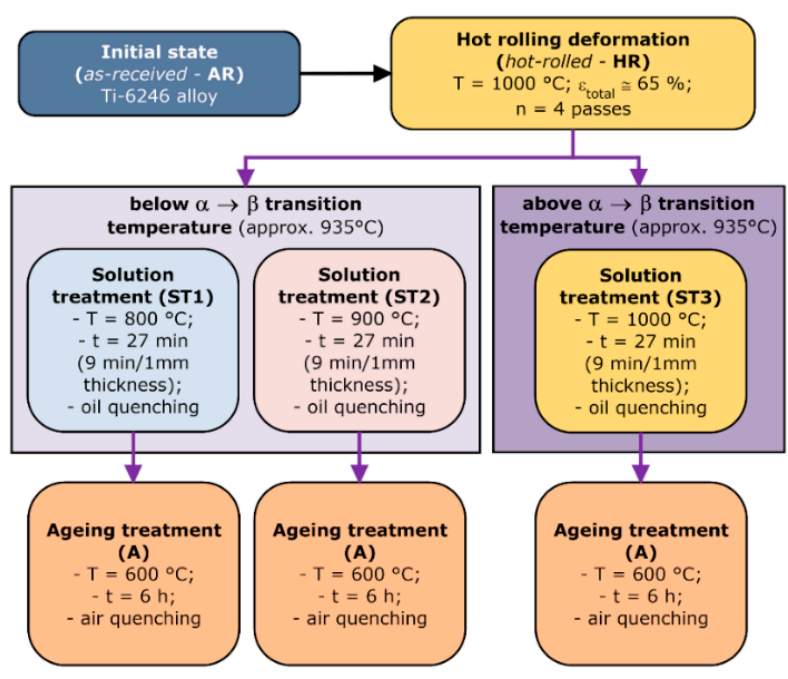

Figure 1. Schematic representation of the applied thermomechanical processing route.

After hot rolling, the samples were solution treated using different temperatures, below and above $\alpha$-Ti $\rightarrow \beta$-Ti transition temperature ( $\beta$-transus). Considering that in the case of Ti-6246 alloy the $\beta$-transus temperature is situated close to $935{ }^{\circ} \mathrm{C}$ [31], the first set of samples was solution treated, at a temperature below $\beta$-transus, at $800^{\circ} \mathrm{C}$ (ST1-state), the second set was solution treated, at a temperature close to $\beta$-transus, at $900{ }^{\circ} \mathrm{C}$ (ST2-state) and, finally, the third set was solution treated, above $\beta$-transus, at $1000{ }^{\circ} \mathrm{C}$ (ST3-state). Solution treatment duration for all samples was fixed to $9 \mathrm{~min} / 1 \mathrm{~mm}$ sample thickness (27 $\mathrm{min} / 3 \mathrm{~mm}$ thickness). All solution-treated samples were oil-quenched (OQ), to induce the formation of secondary phases (i.e., $\alpha^{\prime}$-Ti $/ \alpha^{\prime \prime}$-Ti phases). In order to obtain an adequate combination of mechanical properties, high strength properties and increased ductility, one must complete the TM processing route with a final heat treatment (ageing), aimed to reduce the weight-fraction of secondary phases, i.e., $\alpha^{\prime}$-Ti and $\alpha^{\prime \prime}$-Ti phases, by applying an ageing treatment [32-36]. The ageing treatment must be performed to a temperature high enough to allow $\alpha^{\prime}$-Ti $\rightarrow \alpha$-Ti and/or $\alpha^{\prime \prime}-\mathrm{Ti} \rightarrow \beta$-Ti transformations, stress relieving and reordering/restructuring phenomena in parent $\alpha$-Ti/ $\beta$-Ti phases. The ageing treatment parameters are as following: treatment temperature $600^{\circ} \mathrm{C}$, treatment duration $6 \mathrm{~h}$ and air quenching.

All TM processed specimens were investigated from microstructural and mechanical behaviour point of view. In order to perform the microstructural investigations the following metallographic preparation procedure was applied to all samples: the samples were hot-mounted in conductive phenolic powder (at $150{ }^{\circ} \mathrm{C}$ for $7 \mathrm{~min}$ ) and metallographically ground from 180 to 1200-grit SiC paper, in six steps ( $60 \mathrm{~s} / \mathrm{step})$, then polished with $6 \mu \mathrm{m}$ and $1 \mu \mathrm{m}$ polycrystalline diamond suspension (180 s/step), followed by super-polishing with $0.05 \mu \mathrm{m}$ colloidal silica suspension mixed with a $1 / 5$ ratio of $20 \% \mathrm{H}_{2} \mathrm{O}_{2}$ (300 s/step) and finally vibro-polishing with $0.02 \mu \mathrm{m}$ colloidal silica mixed with a $1 / 5$ ratio of $20 \% \mathrm{H}_{2} \mathrm{O}_{2}$ (3.6 ks). The X-ray diffraction (XRD) analysis was performed to identify constituent phases in the analysed samples and XRD measurements were performed using a Malvern Panalytical Empirean (Malvern Panalytical BV, Almelo, Netherlands) diffractometer. The microstructure was investigated by optical microscopy (OM), scanning electron microscopy (SEM) and X-ray diffraction (XRD) techniques, with the aim of observing the constituent phases and their morphology. A Metkon IMM 901 (Metkon Instruments, Bursa, Turkey) inverted optical microscope was used to perform optical microstructural investigations, while a SEM-TESCAN Vega II-XMU (TESCAN, Brno, Czech Republic) microscope was used to perform SEM microstructural investigations. In order to compute the alloy's chemical composition, the SEM was fitted with a Bruker Quantax 6/30 xFlash (Bruker Corporation, Billerica, MA, USA) detector. All TM processed specimens were, also, tensile and hardness tested, at ambient temperature, to determine the following mechanical properties: ultimate tensile strength $\left(\sigma_{\mathrm{UTS}}\right), 0.2$ yield strength $\left(\sigma_{0.2}\right)$, elongation to fracture $\left(\varepsilon_{f}\right)$ and microhardness $(\mathrm{HV})$. "Dog-bone" shape 
samples, with the calibrated part of $50 \times 5 \times 1.5 \mathrm{~mm}^{3}$, were tensile tested at $2 \mathrm{~mm} / \mathrm{s}$ crosshead speed. Tensile testing measurements were performed using an INSTRON 3382 (INSTRON, Norwood, MA, USA) universal testing equipment, while hardness testing an INNOVATEST Falcon 500 equipment (INNOVATEST Europe BV, Maastricht, Netherlands).

In order to compute the average values of all investigated mechanical properties, the following procedure was applied: for each TM processed specimen, three identical samples were tested in identical conditions; computed data were statistically analysed and the standard deviation was determined. All data were rounded as following: strength properties to the nearest whole number, in $\mathrm{MPa}$, while the elongation to $0.5 \%$ and microhardness to $0.1 \mathrm{HV} 1$.

\section{Results and Discussion}

\subsection{Microstructure Evolution during TM Processing of Ti-6246 Alloy}

Figure 2 shows the optical microscopy (OM) images of as-received (AR) Ti-6246 alloy. One can observe that the microstructure consists of a large number of millimetre-size grains, with an average grain-size exceeding $2 \mathrm{~mm}$. Besides millimetre-size grains, the microstructure shows the presence of a small fraction of sub-millimetre-size grains, with an average grain-size close to $500 \mu \mathrm{m}$ (see Figure 2a). All grains show the presence of multiple $\alpha$-Ti/ $\beta$-Ti colonies, each possessing different spatial orientation and showing a fine lamellae/plate-like microstructure composed of two different phases, $\alpha$-Ti and $\beta$-Ti phase respectively, with a typical Widmanstätten/basket-weave-type morphology (see Figure 2b).
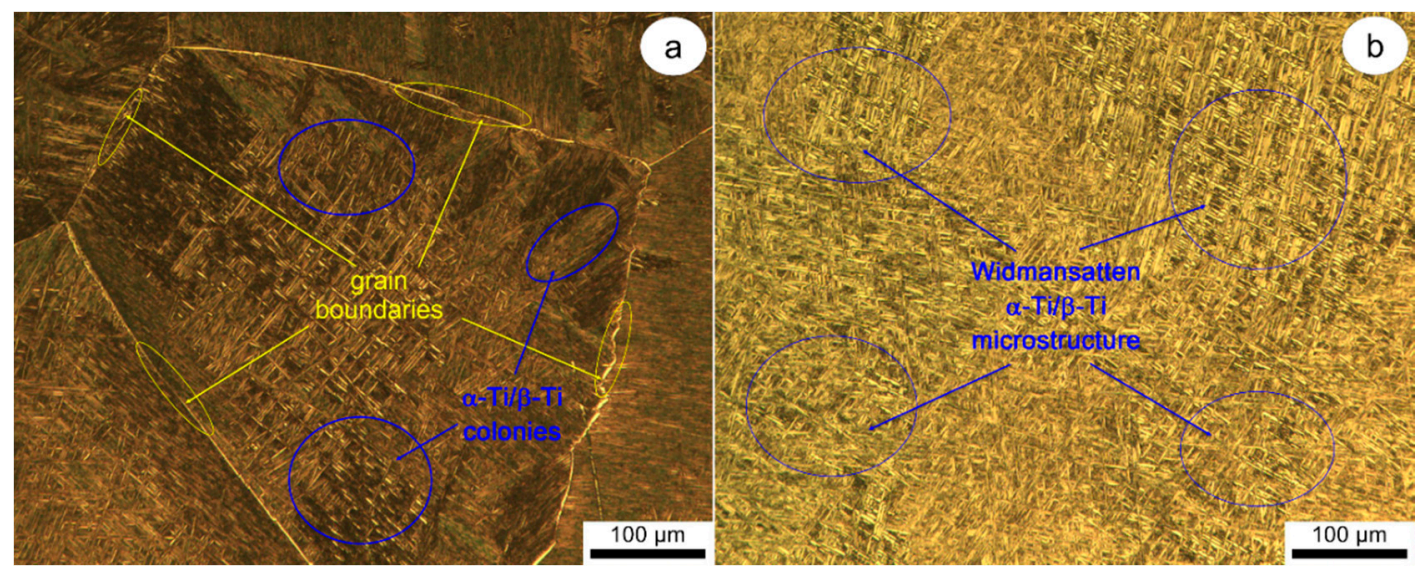

Figure 2. (a,b) Optical microscopy (OM) images of as-received (AR) state in different investigation areas.

Figure 3 shows typical SEM-BSE (SEM-back scattered electrons) microstructural images of as-received (AR) Ti-6246 alloy at different magnifications. One can observe that a grain consists of adjacent colonies (see Figure 3a) of alternate lamellae/plate-like structures with the same orientation (see Figure 3b). One can identify the presence of two constituent phases, first one-coloured in light-grey (indicating the presence of alloying elements with a higher atomic number), and second one-coloured in dark-grey (indicating the presence of alloying elements with a lower atomic number) (see Figure 3c). Both phases show an average lamella/platelet thickness below $1 \mu \mathrm{m}$ (see Figure 3c). The XRD analysis shows that the observed phases are identified as $\alpha$-Ti and, respectively, $\beta$-Ti phases (see Figure $3 \mathrm{~d}$ ). The $\alpha$-Ti phase showed a hexagonal close packet (HCP) crystalline structure with the lattice parameters close to $\mathrm{a}=0.294 \mathrm{~nm}$ and $\mathrm{c}=0.467 \mathrm{~nm}$, while $\beta$-Ti phase showed a body-centred cubic (BCC) crystalline structure with the lattice parameters close to a $=0.327 \mathrm{~nm}$. 

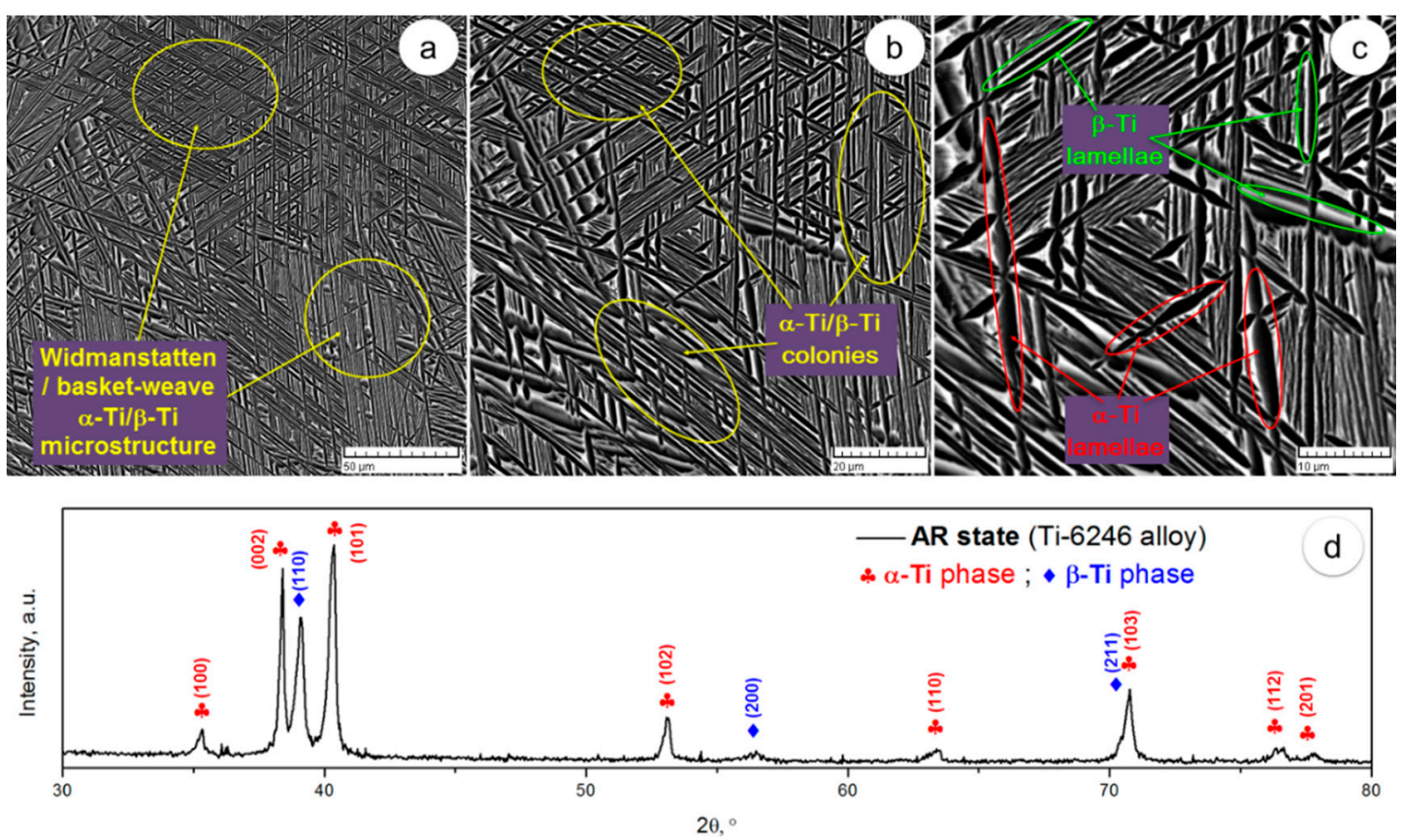

Figure 3. (a-c) SEM-back scattered electrons (SEM-BSE) images of as-received (AR) Ti-6246 alloy in different magnifications; (d) X-ray diffraction (XRD) spectra of as-received (AR) Ti-6246 alloy.

The dispersion maps of the main alloying elements (Ti, $\mathrm{Al}, \mathrm{Sn}, \mathrm{Zr}, \mathrm{Mo}$ and $\mathrm{Fe}$ ) within the microstructure are presented in Figure $4 \mathrm{~b}-\mathrm{g}$. The EDS analysis of the dispersion maps, also, indicates the presence of two main constituent phases, first one enriched in $\alpha$-stabilising elements, such as: Ti (Figure $4 \mathrm{~b}$ ) and $\mathrm{Al}$ (Figure $4 \mathrm{c}$ ) and depleted in $\beta$-stabilising elements, such as: Mo (Figure $4 \mathrm{~d}$ ) and $\mathrm{Zr}$ (Figure 4e) and the second one enriched in $\beta$-stabilising elements, such as: Mo (Figure $4 \mathrm{~d}$ ) and $\mathrm{Zr}$ (Figure $4 \mathrm{e}$ ) and depleted in $\alpha$-stabilising elements, such as: Ti (Figure $4 \mathrm{~b}$ ) and $\mathrm{Al}$ (Figure $4 \mathrm{c}$ ). All other alloying elements show an almost uniform distribution within the microstructure ( $\mathrm{Sn}-$ Figure $4 \mathrm{f}$ and $\mathrm{Fe}-$ Figure 4g). Based on EDS analysis one can assume that the $\alpha$-Ti phase is enriched in Ti and Al and, therefore coloured in dark-grey, while the $\beta$-Ti phase is enriched in $\mathrm{Mo}$ and $\mathrm{Zr}$ and, therefore coloured in light-grey. Figure 4 h shows the EDS spectra of Ti-6246 alloy in AR. The computed chemical composition is presented in Table 1.

Overall, the microstructure analysis shows that the Ti-6246 alloy obtained by a double VAR synthesis route consists of a homogenous microstructure with millimetre-size grains, each grain showing the presence of multiple coherent colonies of alternate $\alpha$-Ti/ $\beta$-Ti lamellae/plate-like structures. No segregations or other defects such as: porosities, inclusions etc., were detected.

Table 1. Chemical composition of as-received (AR) Ti-6246 alloy.

\begin{tabular}{ccccc}
\hline Element & wt. $\%$ & at.\% & Abs. Error (\%) & Rel. Error (\%) \\
\hline Titanium & 81.54 & 82.55 & 2.44 & 2.76 \\
\hline Aluminium & 6.33 & 11.36 & 0.33 & 4.77 \\
\hline Tin & 1.85 & 0.75 & 0.05 & 2.94 \\
\hline Zirconium & 3.91 & 2.08 & 0.16 & 3.79 \\
\hline Molybdenum & 6.24 & 3.15 & 0.24 & 3.54 \\
\hline Iron & 0.14 & 0.12 & 0.12 & 2.77 \\
\hline
\end{tabular}



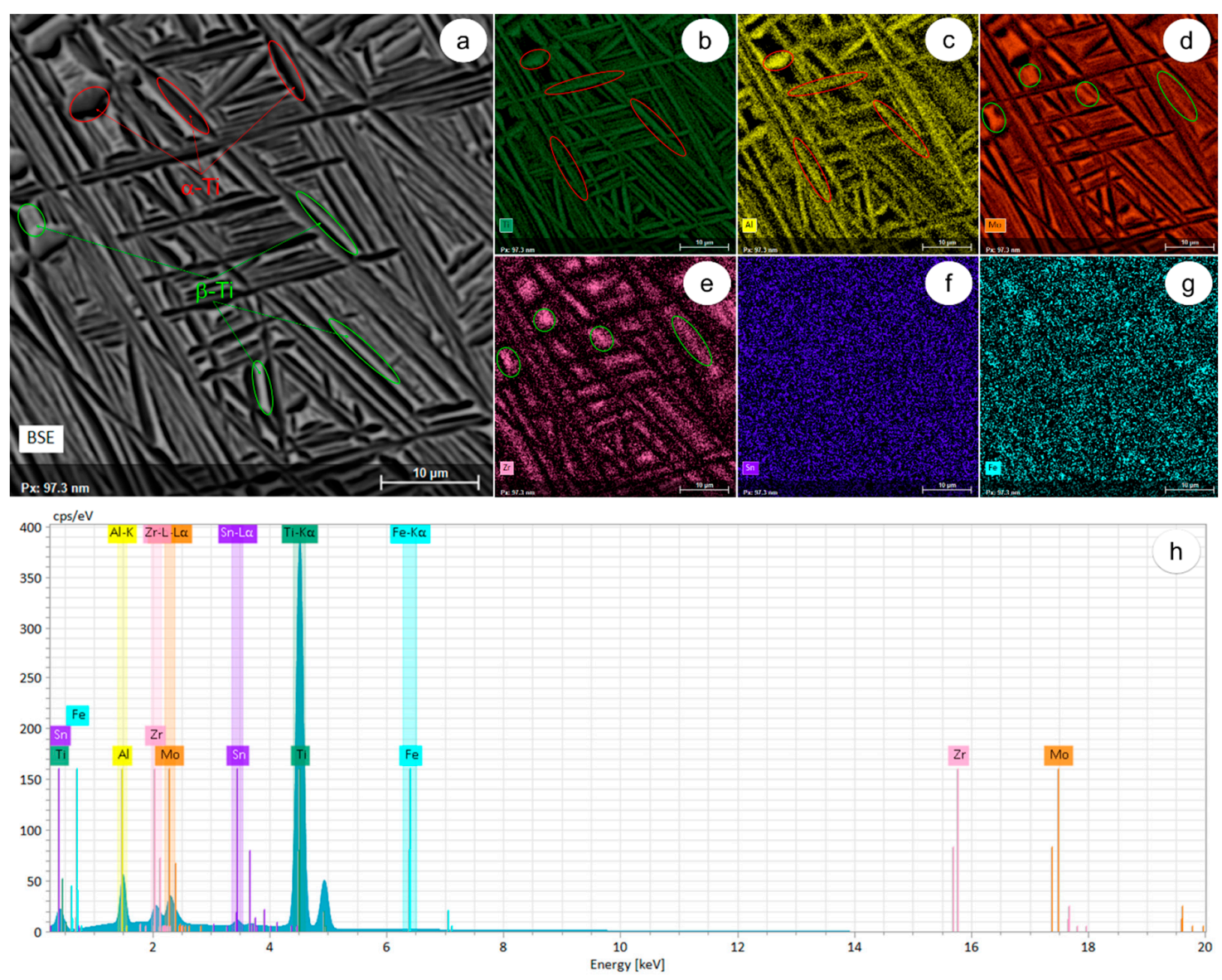

Figure 4. Distribution maps of main alloying elements in as-received (AR) Ti-6246 alloy: (a) SEM-BSE microstructural image; (b) SEM-EDS distribution map of Ti; (c) Al; (d) Mo; (e) Zr; (f) Sn; (g) Fe; (h) global EDS spectra.

Figure 5 shows typical SEM-BSE microstructural images of hot-deformed (HR) Ti-6246 alloy at different magnifications. One can observe that the initial grains are heavily deformed, showing an elongated morphology along the rolling direction, the same observation can be made in the case of the grain's boundary, which also tends to align along the rolling direction (see Figure 5a). Because of high deformation temperature of $1000^{\circ} \mathrm{C}$ (above $\beta$-transus $\approx 935^{\circ} \mathrm{C}$ ) and high applied deformation (total deformation degree $\approx 65 \%$ ) the adjacent $\alpha$-Ti/ $\beta$-Ti colonies are intensely deformed, showing an elongated morphology, with an average thickness close to $15 \mu \mathrm{m}$ (see Figure $5 \mathrm{~b}$ ). The deformed $\alpha-\mathrm{Ti} / \beta$-Ti colonies are separated by thin boundaries, which appear due to applied intense deformation and to the difference in initial spatial orientation of the $\alpha$-Ti/ $\beta$-Ti colonies (see Figure $5 c$ ). The XRD spectra of HR state (see Figure $5 \mathrm{~d}$ ) shows that the diffraction peaks of both $\alpha$-Ti and $\beta$-Ti phases are characterized by large widths (peak broadening), which indicates a low grain-size for both $\alpha$-Ti and $\beta$-Ti phases.

Figure 6 shows typical SEM-BSE microstructural images of solution-treated (ST) Ti-6246 alloy at different temperatures. In the case of ST1 treatment (Figure 6a) one can observe that the heavily deformed grains are fully recrystallised. Both $\alpha$-Ti and $\beta$-Ti phases are fully regenerated as thin alternate lamellae/plate-like structures showing preferred spatial orientation. Besides $\alpha$-Ti and $\beta$-Ti phases, one can notice the presence of a dispersed fine acicular phase, identified as $\alpha^{\prime}$-Ti phase, generated because of rapid cooling at ambient temperature. The $\alpha^{\prime}$-Ti phase shows preferred orientation in relation with the parent $\alpha$-Ti phase because of the special Burgers relation between the $\alpha$-Ti $/ \alpha^{\prime}$-Ti phases [37-40]. In the case of ST2 treatment (Figure 6b) one can observe that the microstructure shows a basket-weave type morphology. The basket-weave morphology shows the presence of interconnected/parallel 
$\alpha-\mathrm{Ti} / \beta$-Ti lamellae, with higher thickness lamellae when comparing to ST1 state. When comparing the average thickness of $\alpha$-Ti with $\beta$-Ti lamella one can observe that the $\alpha$-Ti lamella shows a much higher thickness, suggesting that the heating to ST2 treatment temperature favours recrystallization of $\alpha$-Ti phase. Also, one can notice inside $\alpha$-Ti lamella the presence of $\alpha^{\prime}$-Ti phase, generated because of rapid cooling at ambient temperature, which shows a platelet-like morphology. Analysing the case of ST3 treatment (Figure 6c) one can observe that the microstructure also shows a basket-weave type morphology. The rapid cooling from $1000{ }^{\circ} \mathrm{C}$ to ambient temperature induced the formation of a microstructure consisting in a mixture of a lamellar/ fine acicular dispersion and larger parallel platelets. The parallel platelets were identified as $\alpha^{\prime \prime}$-Ti phase, being generated due to the rapid cooling to ambient temperature of the $\beta$-Ti phase. The $\alpha^{\prime \prime}$-Ti phase shows preferred spatial orientation in relation with parent $\beta$-Ti phase due to the special Burgers relation between the $\beta$-Ti $/ \alpha^{\prime \prime}$-Ti phases [41-44].
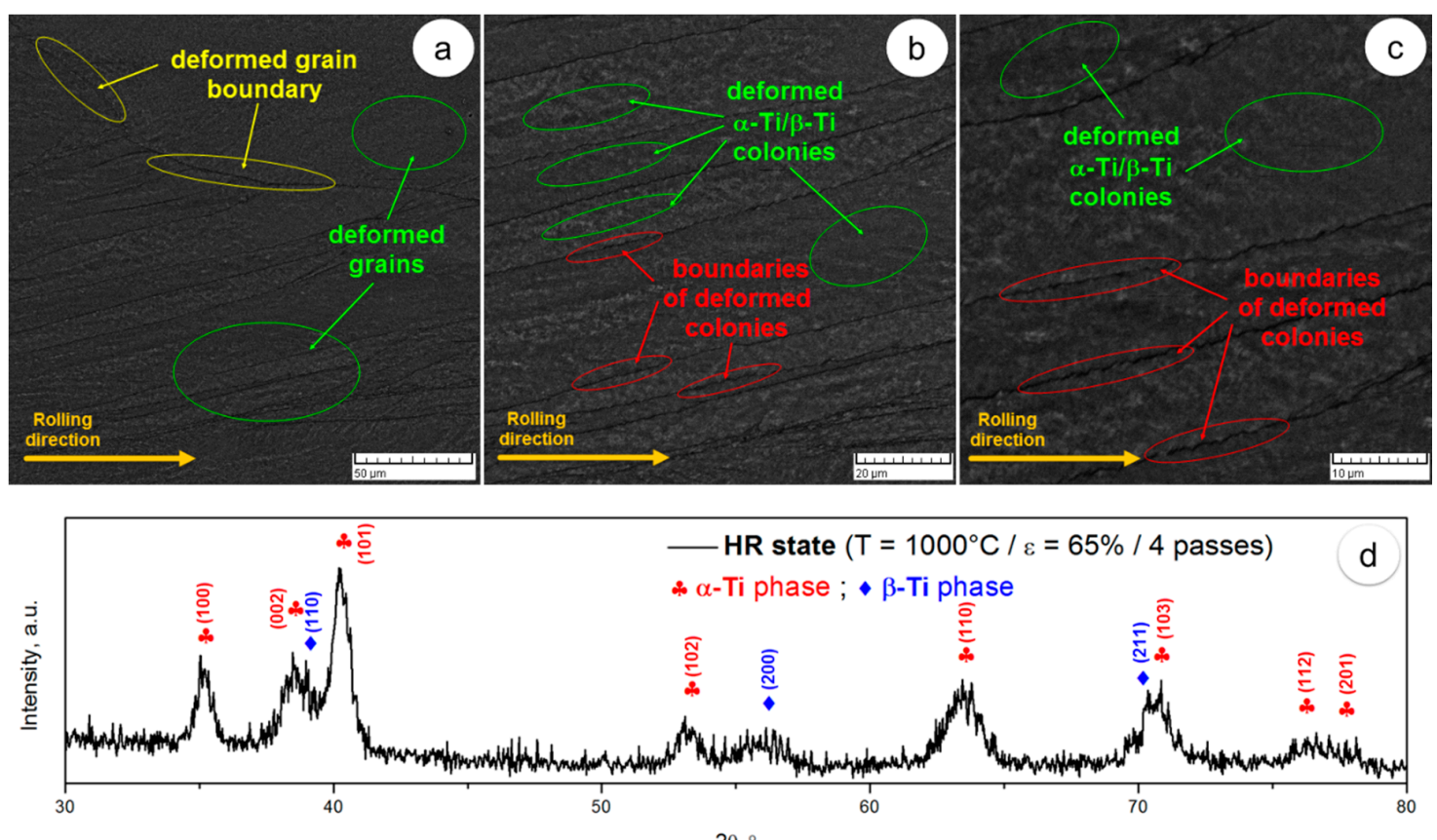

$2 \theta$, $^{\circ}$

Figure 5. (a-c) SEM-BSE images of hot-deformed (HR) state in different magnifications; (d) XRD spectra of HR state.

Considering the ageing temperature $\left(600^{\circ} \mathrm{C}\right)$ and ageing duration $(6 \mathrm{~h})$, one can assume that during ageing the following phenomena occur: stress relieving and thermal induced transformation $\alpha^{\prime}-\mathrm{Ti} / \alpha^{\prime \prime}-\mathrm{Ti}$ $\rightarrow \alpha$-Ti $/ \beta$-Ti. Figure $6 \mathrm{~d}$ shows a typical microstructural image of solution treated at $800{ }^{\circ} \mathrm{C}$ and aged at $600{ }^{\circ} \mathrm{C}(\mathrm{ST} 1+\mathrm{A})$ state. One can observe that the microstructure shows the same morphological aspect, alternate $\alpha-\mathrm{Ti} / \beta$-Ti thin lamellae/plate-like structures, with the initial ST1 state. Because of the ageing treatment, one can notice that no fine acicular phase $\alpha^{\prime}$-Ti is observed, suggesting that the ageing treatment temperature is high enough to induce the $\alpha^{\prime}$-Ti $\rightarrow \alpha$-Ti phase transformation and the treatment duration is long enough to complete the $\alpha^{\prime}-\mathrm{Ti} \rightarrow \alpha$-Ti phase transformation. Analysing the case of solution treated at $900{ }^{\circ} \mathrm{C}$ and aged at $600{ }^{\circ} \mathrm{C}(\mathrm{ST} 2+\mathrm{A})$ state (Figure 6e), it can be observed that the microstructure shows a basket-weave type morphology, with a very fine dispersion of $\alpha$-Ti lamellae within the $\beta$-Ti phase matrix. Also, in this case, one can notice that the ageing treatment induced the $\alpha^{\prime}$-Ti $\rightarrow \alpha$-Ti phase transformation, no traces of $\alpha^{\prime}$-Ti-phase being observed. Analysing the case of solution treated at $1000^{\circ} \mathrm{C}$ and aged at $600{ }^{\circ} \mathrm{C}(\mathrm{ST} 3+\mathrm{A})$ state (Figure $\left.6 \mathrm{f}\right)$, one can observe that the microstructure shows also a basket-weave type morphology, with alternate $\alpha-\mathrm{Ti} / \beta$-Ti thin lamellae/plate-like structures. Besides the $\alpha$-Ti $/ \beta$-Ti phases, one can notice that the ageing treatment induced the $\alpha^{\prime}-\mathrm{Ti} / \alpha^{\prime \prime}-\mathrm{Ti} \rightarrow \alpha$-Ti $/ \beta$-Ti phase transformations, no signs of $\alpha^{\prime}-\mathrm{Ti} / \alpha^{\prime \prime}-\mathrm{Ti}$ phases being visible. 


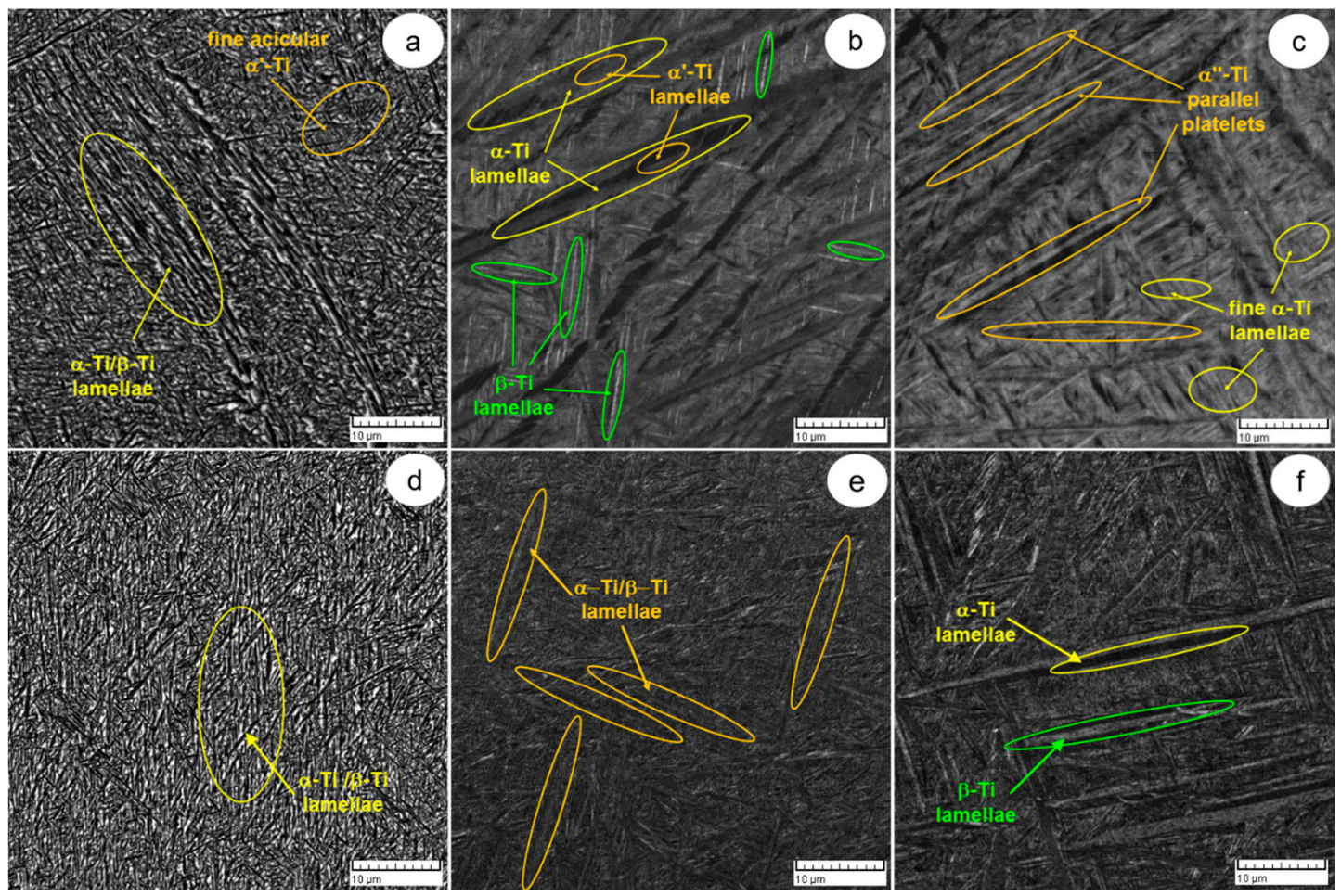

Figure 6. SEM-BSE images of (a) solution treated at $800{ }^{\circ} \mathrm{C}(\mathrm{ST} 1)$ state; (b) solution treated at $900{ }^{\circ} \mathrm{C}$ (ST2) state; (c) solution treated at $1000{ }^{\circ} \mathrm{C}$ (ST3) state; (d) solution treated at $800{ }^{\circ} \mathrm{C}$ and aged at $600{ }^{\circ} \mathrm{C}$ $(\mathrm{ST} 1+\mathrm{A})$ state; $(\mathbf{e})$ solution treated at $900{ }^{\circ} \mathrm{C}$ and aged at $600{ }^{\circ} \mathrm{C}(\mathrm{ST} 2+\mathrm{A})$ state; (f) solution treated at $1000{ }^{\circ} \mathrm{C}$ and aged at $600{ }^{\circ} \mathrm{C}(\mathrm{ST} 3+\mathrm{A})$ state.

Overall, analysing solution-treated states (ST1, ST2, ST3) and aged states (ST1 + A, ST2 + A, ST3 + A) from morphological point of view, one can assume that the ageing treatment induced important microstructural changes, mainly by promoting $\alpha^{\prime}-\mathrm{Ti} / \alpha^{\prime \prime}-\mathrm{Ti} \rightarrow \alpha-\mathrm{Ti} / \beta$-Ti phase transformations, the final microstructure consisting of only a mixture of $\alpha-\mathrm{Ti} / \beta$-Ti phases. If one considers the specific mechanical behaviour of each phase $\left(\alpha^{\prime}-\mathrm{Ti} / \alpha^{\prime \prime}\right.$-Ti phases possessing higher strength, but limited ductility properties in comparison with the parent $\alpha-\mathrm{Ti} / \beta$-Ti phases $[16,17])$, one can also expect an increase in the alloy's ductility as a result of ageing.

Figure 7 shows typical XRD spectra of solution treated (ST) states at different temperatures. In the case of ST1 treatment, one can observe the presence of diffraction peaks belonging to $\beta$-Ti, $\alpha$-Ti and $\alpha^{\prime}$-Ti phases (see Figure 7a). The $\alpha$-Ti and $\alpha^{\prime}$-Ti phases were indexed in the HCP crystalline system, both showing close lattice parameters (close to $\mathrm{a}=0.294 \mathrm{~nm}$ and $\mathrm{c}=0.467 \mathrm{~nm}$ ) and therefore being difficult to distinguish between them. The differences in lattice parameters are due to the supersaturation in $\beta$-stabilising elements of the $\alpha^{\prime}$-Ti phase in comparison with the $\alpha$-Ti phase $[37,38]$. In the case of ST2 treatment, one can observe the presence of diffraction peaks belonging to $\beta$-Ti, $\alpha$-Ti and $\alpha^{\prime}-\mathrm{Ti}$ phases (see Figure 7b). The analysis of diffraction peaks relative intensities is showing a tendency of phase texturing along with certain crystallographic directions, suggesting preferred crystallographic grain-growth for all phases, supporting SEM-BSE microstructural observations (see Figure 6b). In the case of ST3 treatment one can observe the presence of diffraction peaks belonging to $\alpha$-Ti, $\beta$-Ti, $\alpha^{\prime \prime}$-Ti and possible $\alpha^{\prime}$-Ti phases (see Figure $7 \mathrm{c}$ ). Because of the heating at $1000{ }^{\circ} \mathrm{C}$, above $\beta$-transus temperature $\approx 935^{\circ} \mathrm{C}$, and rapid cooling at ambient temperature the $\alpha^{\prime \prime}$-Ti phase is generated from parent $\beta$-Ti phase $[45,46]$. The $\alpha^{\prime \prime}$-Ti phase was indexed in the orthorhombic crystalline system, with the lattice parameters close to $a=0.296 \mathrm{~nm}, \mathrm{~b}=0.496 \mathrm{~nm}$ and $\mathrm{c}=0.468 \mathrm{~nm}$. Analysing the relative intensities of the diffraction peaks one can notice also, a tendency of preferred crystallographic grain-growth for all phases, supporting SEM-BSE microstructural observations (see Figure 6c). In all cases, if one analyses the diffraction peaks widths (peaks broadening), it can be observed that the 
peaks are indicating a low grain-size for all observed phases, supporting SEM-BSE microstructural observations (see Figure 6).
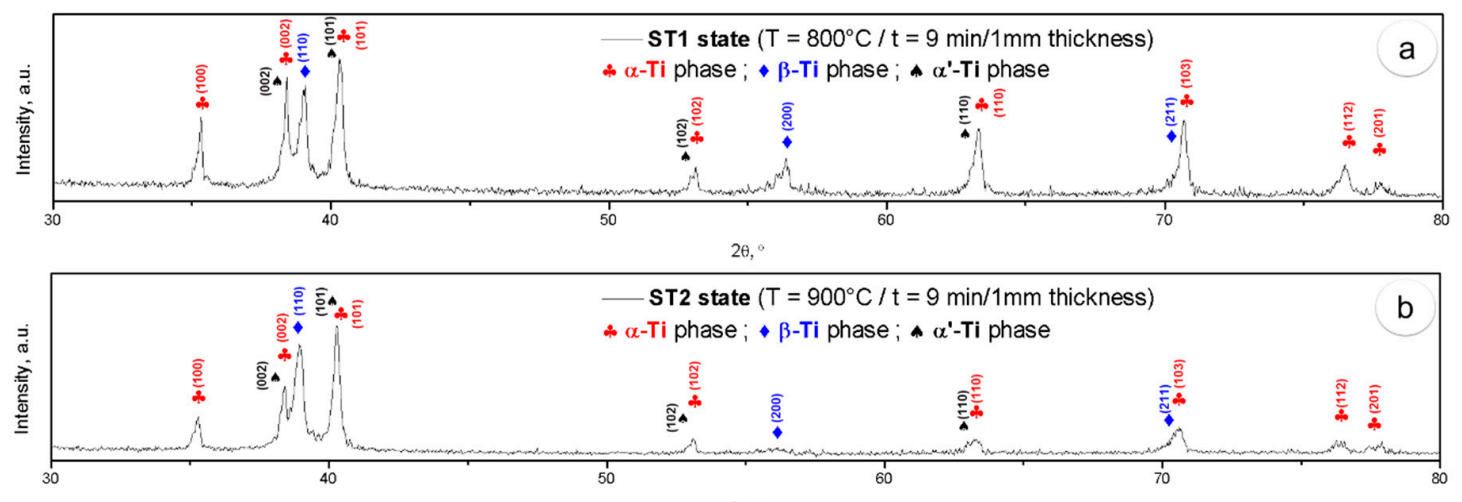

$2 \theta^{\circ}$

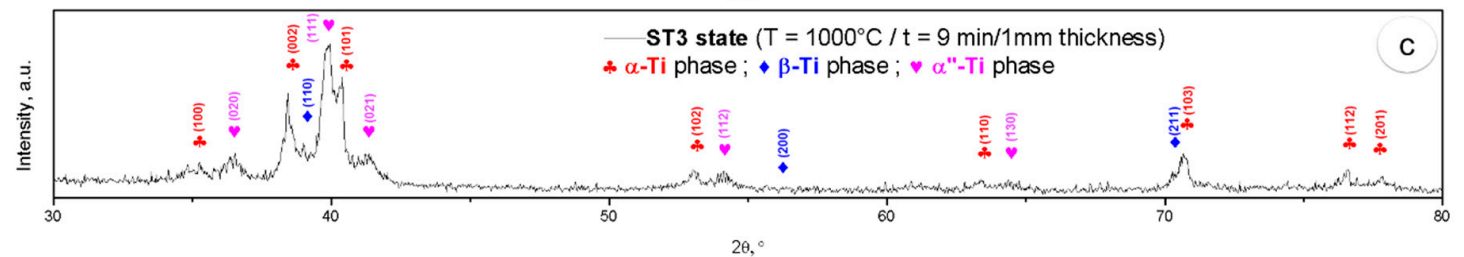

Figure 7. XRD spectra of (a) solution treated at $800{ }^{\circ} \mathrm{C}$ state (ST1); (b) solution treated at $900{ }^{\circ} \mathrm{C}$ state (ST2); (c) solution treated at $1000{ }^{\circ} \mathrm{C}$ state (ST3).

\subsection{Mechanical Behaviour during TM Processing of Ti-6246 Alloy}

The analysis of mechanical behaviour considered the following mechanical properties: ultimate tensile strength $\left(\sigma_{\mathrm{UTS}}\right), 0.2$ yield strength $\left(\sigma_{0.2}\right)$, elongation to fracture $\left(\varepsilon_{f}\right)$ during tensile testing and microhardness (HV1). Computed values of considered mechanical properties are presented in Table 2.

Table 2. Mechanical properties of TM processed Ti-6246 alloy.

\begin{tabular}{|c|c|c|c|c|}
\hline \multirow[b]{2}{*}{ Structural State } & \multicolumn{4}{|c|}{ Mechanical Properties } \\
\hline & $\begin{array}{c}\text { Ultimate Sensile } \\
\text { Strength, } \sigma_{\text {UTS }}(\mathrm{MPa})\end{array}$ & $\begin{array}{c}0.2 \text { Yield Strength, } \\
\sigma_{0.2}(\mathrm{MPa})\end{array}$ & $\begin{array}{l}\text { Elongation to } \\
\text { Fracture, } \varepsilon_{f}(\%)\end{array}$ & $\begin{array}{l}\text { Microhardness, } \\
\text { HV1 }\end{array}$ \\
\hline As-received (AR) & $1057 \pm 14$ & $967 \pm 11$ & $12.9 \pm 1.8$ & $305.2 \pm 16.9$ \\
\hline Hot-deformed at $1000{ }^{\circ} \mathrm{C}(\mathrm{HR})$ & $1012 \pm 11$ & $902 \pm 14$ & $3.2 \pm 0.6$ & $417.8 \pm 6.1$ \\
\hline Solution treated at $\mathrm{T}=800^{\circ} \mathrm{C}(\mathrm{ST} 1)$ & $1113 \pm 14$ & $985 \pm 10$ & $5.3 \pm 0.8$ & $385.1 \pm 10.1$ \\
\hline Solution treated at $\mathrm{T}=900^{\circ} \mathrm{C}(\mathrm{ST} 2)$ & $1205 \pm 12$ & $1014 \pm 13$ & $8.1 \pm 1.2$ & $312.4 \pm 17.1$ \\
\hline Solution treated at $\mathrm{T}=1000{ }^{\circ} \mathrm{C}(\mathrm{ST} 3)$ & $961 \pm 12$ & $747 \pm 15$ & $7.2 \pm 0.9$ & $339.8 \pm 21.3$ \\
\hline $\begin{array}{l}\text { Solution treated at } \mathrm{T}=800^{\circ} \mathrm{C}+ \\
\text { ageing treated at } \mathrm{T}=600^{\circ} \mathrm{C}(\mathrm{ST} 1+\mathrm{A})\end{array}$ & $1144 \pm 13$ & $991 \pm 12$ & $6.5 \pm 0.9$ & $325.2 \pm 11.9$ \\
\hline $\begin{array}{l}\text { Solution treated at } \mathrm{T}=900^{\circ} \mathrm{C}+ \\
\text { ageing treated at } \mathrm{T}=600^{\circ} \mathrm{C}(\mathrm{ST} 2+\mathrm{A})\end{array}$ & $1279 \pm 15$ & $1161 \pm 14$ & $10.1 \pm 1.3$ & $425.2 \pm 4.5$ \\
\hline $\begin{array}{l}\text { Solution treated at } \mathrm{T}=1000^{\circ} \mathrm{C}+ \\
\text { ageing treated at } \mathrm{T}=600^{\circ} \mathrm{C}(\mathrm{ST} 3+\mathrm{A})\end{array}$ & $1044 \pm 12$ & $919 \pm 13$ & $5.7 \pm 0.9$ & $442.6 \pm 9.6$ \\
\hline
\end{tabular}

Analysing the data obtained during mechanical testing, one can observe that the hot deformation induces a decrease in strength properties $\left(\sigma_{\mathrm{UTS}}=1012 \pm 11 \mathrm{MPa}, \sigma_{0.2}=902 \pm 14 \mathrm{MPa}\right)$ and ductility $\left(\varepsilon_{f}=3.2 \pm 0.6 \%\right)$ when comparing with the as-received condition $\left(\sigma_{\mathrm{UTS}}=1057 \pm 14 \mathrm{MPa}, \sigma_{0.2}=967 \pm\right.$ $11 \mathrm{MPa}, \varepsilon_{f}=12.9 \pm 1.8 \%$ ) (see Table 2). The observed decrease must be linked to the effects induced by the deformation in the alloy's microstructure. The initial grains, containing multiple coherent colonies of alternate $\alpha$-Ti/ $\beta$-Ti lamellae/plate-like structures, are intensely deformed, highly increasing the microstructure defects density, inducing strain-hardening. The microhardness evolution shows an 
increase, to approx. $417.8 \pm 6.1 \mathrm{HV} 1$, when comparing with the as-received condition $(305.2 \pm 16.9 \mathrm{HV} 1)$, as a result also of strain-hardening.

Analysing the effects induced by the applied solution treatments (ST1, ST2, ST3) on the mechanical properties, important changes are revealed, mainly due to the induced changes in the alloy's microstructure. If the treatment temperature is below $\beta$-transus and the treatment duration is long enough, the deformed microstructure can fully recrystallize, drastically decreasing the microstructure defects density and, therefore, increasing both strength and ductility properties. One must consider the influence of $\alpha$-Ti/ $\beta$-Ti grain-size on mechanical properties, which, according to Hall-Petch relation, shows that strength properties are increasing with decreasing of average grain-size [47]:

$$
\sigma_{y}=\sigma_{0}+\frac{k}{\sqrt{d}}
$$

where: $\sigma_{y}$-yield strength, $\sigma_{0}$ —starting stress for dislocation movement, $k$ - grain boundary resistance, $d$-average grain-size.

As shown in Figure $6 a-c$, the microstructure shows the presence of low grain-size phases $\left(\alpha-\mathrm{Ti} / \beta-\mathrm{Ti} / \alpha^{\prime}-\mathrm{Ti} / \alpha^{\prime \prime}-\mathrm{Ti}\right)$ which, according to the Hall-Petch relation, should have a positive effect on the alloy's mechanical behaviour.

Besides the influence of strain-hardening and average grain-size of constituent phases, one must consider also the mixing law of phases, which states that a higher weight fraction of a certain phase will have a stronger influence on material's overall exhibited properties. As observed, in the case of ST states (Figure $6 \mathrm{a}-\mathrm{c}$ ), the microstructure consists of a mixture of phases, namely the main $\alpha$-Ti and $\beta$-Ti phases and thermally induced $\alpha^{\prime}$-Ti and $\alpha^{\prime \prime}$-Ti phases. If the ST temperature is below $\beta$-transus, then the $\alpha^{\prime}$-Ti phase is thermally induced from the parent $\alpha$-Ti phase, when a higher cooling rate is applied; the $\alpha^{\prime}$-Ti phase showing the same crystalline system and almost identical lattice parameters with the parent $\alpha$-Ti phase (inducing difficulties in discriminating between the parent $\alpha$-Ti and $\alpha^{\prime}$-Ti diffraction peaks-see Figure 7) [37-40]. No transformation can be noticed in the case of parent $\beta$-Ti phase. If the ST temperature is above $\beta$-transus, then the $\alpha^{\prime \prime}$-Ti phase is thermally induced from the parent $\beta$-Ti phase, when a higher cooling rate is applied [41-44], showing different crystalline system and lattice parameters (easily to discriminate between the parent $\beta$-Ti and $\alpha$ "-Ti diffraction peaks-see Figure 7).

Considering the specific mechanical behaviour of all observed phases, $\alpha$-Ti phase exhibiting the highest strength, $\beta$-Ti phase the highest ductility, while $\alpha^{\prime}$-Ti and $\alpha^{\prime \prime}$-Ti phases a mixed behaviour (lower strength/ductility in comparison with parent $\alpha$-Ti/ $\beta$-Ti phases) $[48,49]$ and their weight-fractions, one can make the following assumptions. First, when ST temperature is far below $\beta$-transus $\approx 935^{\circ} \mathrm{C}$ (i.e., $800{ }^{\circ} \mathrm{C}-\mathrm{ST} 1$ case), during heating, the microstructure consists of a mixture of $\alpha$-Ti and $\beta$-Ti phases, no $\alpha$-Ti $\rightarrow \beta$-Ti transformation occurs, but only recrystallization in the $\alpha$-Ti phase case and restructuring in the $\beta$-Ti phase. During rapid cooling to ambient temperature the $\alpha-\mathrm{Ti} \rightarrow \alpha^{\prime}-\mathrm{Ti}$ transformation may occur; after cooling the microstructure consisting of a mixture of $\alpha$-Ti, $\beta$-Ti and $\alpha^{\prime}$-Ti phases (see Figures $6 \mathrm{a}$ and 7a) and, as a consequence, an increase in both strength $\left(\sigma_{\mathrm{UTS}}=1113 \pm\right.$ $\left.14 \mathrm{MPa}, \sigma_{0.2}=985 \pm 10 \mathrm{MPa}\right)$ and ductility $\left(\varepsilon_{f}=5.3 \pm 0.8 \%\right)$ properties is recorded when comparing with the initial HR state $\left(\sigma_{\text {UTS }}=1012 \pm 11 \mathrm{MPa}, \sigma_{0.2}=902 \pm 14 \mathrm{MPa}, \varepsilon_{f}=3.2 \pm 0.6 \%\right)$. Second, when ST temperature is just below $\beta$-transus $\approx 935{ }^{\circ} \mathrm{C}$ (i.e., $900{ }^{\circ} \mathrm{C}-\mathrm{ST} 2$ case), during rapid cooling to ambient temperature, the $\alpha$-Ti $\rightarrow \alpha^{\prime}$-Ti transformation occurs; after cooling the microstructure consists of a mixture of $\alpha$-Ti, $\beta$-Ti and $\alpha^{\prime}$-Ti phases (see Figures $6 \mathrm{~b}$ and $7 \mathrm{~b}$ ), with a higher weight-fraction of transformed $\alpha^{\prime}$-Ti phase and, as a consequence, further increases in both strength and ductility properties are recorded $\left(\sigma_{\mathrm{UTS}}=1205 \pm 12 \mathrm{MPa}, \sigma_{0.2}=1014 \pm 13 \mathrm{MPa}, \varepsilon_{f}=8.1 \pm 1.2 \%\right)$. Third, when ST temperature is above $\beta$-transus $\approx 935^{\circ} \mathrm{C}$ (i.e., $1000{ }^{\circ} \mathrm{C}-\mathrm{ST} 3$ case), during the treatment, the $\alpha$-Ti $\rightarrow$ $\beta$-Ti transformation occurs; the microstructure consisting only in $\beta$-Ti phase. During rapid cooling to ambient temperature, the $\beta$-Ti $\rightarrow \alpha^{\prime \prime}$-Ti transformation occurs. Also, during cooling $\beta$-Ti $\rightarrow \alpha$-Ti $\rightarrow$ $\alpha^{\prime}$-Ti transformations can be induced. After cooling, the microstructure usually consists of a mixture of $\alpha-\mathrm{Ti}, \beta-\mathrm{Ti}, \alpha^{\prime \prime}$-Ti and $\alpha^{\prime}$-Ti phases (see Figures $6 \mathrm{c}$ and $7 \mathrm{c}$ ), with a higher weight-fraction of transformed 
$\alpha^{\prime \prime}$-Ti phase and as a consequence, a decrease in strength and an increase in ductility are recorded $\left(\sigma_{\text {UTS }}=961 \pm 12 \mathrm{MPa}, \sigma_{0.2}=747 \pm 15 \mathrm{MPa}, \varepsilon_{f}=7.2 \pm 0.9 \%\right.$ ).

Analysing the case of ageing treatment performed on ST1 solution treated samples (ST1 + A), one can notice that both strength and ductility properties are slightly increased $\left(\sigma_{\text {UTS }}=1144 \pm\right.$ $\left.13 \mathrm{MPa}, \sigma_{0.2}=991 \pm 12 \mathrm{MPa}, \varepsilon_{f}=6.5 \pm 0.9 \%\right)$ when comparing with the initial ST1 ones $\left(\sigma_{\mathrm{UTS}}=1113 \pm\right.$ $14 \mathrm{MPa}, \sigma_{0.2}=985 \pm 10 \mathrm{MPa}, \varepsilon_{f}=5.3 \pm 0.8 \%$ ), because of the effects induced by the ageing treatment. As a possible explanation for this behaviour, one must consider the occurrence of stress-relieving phenomena, which decreases the microstructural defects density (i.e., dislocations, voids, high elastic strains and residual stress fields etc.); the defects can be lowered by applying a thermal treatment, inducing stress relieved phenomena. Analysing the microhardness evolution, one can notice an important decrease from $385.1 \pm 10.1$ HV1 (ST1 state) to $325.2 \pm 11.9$ HV1 (ST1 + A state), due to the stress relieving and also due to the decreased weight-fraction of $\alpha^{\prime}$-Ti phase.

Analysing the case of ageing treatment performed on ST2 solution-treated samples (ST2 + A), one can also notice that both strength and ductility properties are slightly increased $\left(\sigma_{\text {UTS }}=1279 \pm 15 \mathrm{MPa}\right.$, $\left.\sigma_{0.2}=1161 \pm 14 \mathrm{MPa}, \varepsilon_{f}=10.1 \pm 1.3 \%\right)$ when comparing with the initial ST1 ones $\left(\sigma_{\text {UTS }}=1205 \pm\right.$ $\left.12 \mathrm{MPa}, \sigma_{0.2}=1014 \pm 13 \mathrm{MPa}, \varepsilon_{f}=8.1 \pm 1.2 \%\right)$. Analysing the microhardness evolution, one can notice an important increase from $312.4 \pm 17.1 \mathrm{HV} 1$ (ST2 state) to $425.2 \pm 4.5 \mathrm{HV} 1$ (ST2 + A state). In the case of ageing treatment performed on ST3 solution-treated samples (ST3 + A), one can notice that strength properties are increasing $\left(\sigma_{\text {UTS }}=1044 \pm 12 \mathrm{MPa}, \sigma_{0.2}=919 \pm 13 \mathrm{MPa}\right)$, while ductility is decreasing $\left(\varepsilon_{f}=5.7 \pm 0.9 \%\right)$ when comparing with the initial ST3 ones $\left(\sigma_{\text {UTS }}=961 \pm 12 \mathrm{MPa}, \sigma_{0.2}=747 \pm 15 \mathrm{MPa}\right.$, $\left.\varepsilon_{f}=7.2 \pm 0.9 \%\right)$. Analysing the microhardness evolution, one can also notice an important increase from $339.8 \pm 21.3$ HV1 (ST3 state) to $442.6 \pm 9.6$ HV1 (ST3 + A state).

In order to explain this behaviour, besides stress relieving and $\alpha^{\prime}-\mathrm{Ti} / \alpha^{\prime \prime}-\mathrm{Ti} \rightarrow \alpha-\mathrm{Ti} / \beta-\mathrm{Ti}$ transformations, one must consider the influence of $\beta-\mathrm{Ti} \rightarrow \alpha$-Ti transformation, which can occur if the ageing duration is long enough [50-52]. When $\alpha$-Ti phase is generated during ageing from the parent $\beta$-Ti phase, it shows a very fine dispersion within the parent $\beta$-Ti phase, acting as dispersion strengthening particles, inducing an important influence on the alloy's exhibited mechanical behaviour, especially on microhardness [50-52]. In the case of Ti-6246 alloy, it was showed that the microhardness can vary from 300 to $550 \mathrm{HV}$ as a function of ageing treatment temperature and duration $[50,51]$. Another important transformation that can occur is represented by the $\beta-\mathrm{Ti} \rightarrow \omega-\mathrm{Ti}$ phase transformation [53-56]. The $\omega$-Ti phase shows a fine nanometre-size particles dispersion within the parent $\beta$-Ti phase, increasing strength and decreasing ductility properties (strengthening effects) and inducing important embrittlement [57-60].

Analysing the weight-fraction of $\beta$-Ti phase in ST1 + A, ST2 + A and ST3 + A states (see Figure 6), one can notice that the weight-fraction of $\beta$-Ti phase increases with increase in the solution treatment temperature and, as a consequence, the weight-fraction of transformed $\alpha$-Ti $/ \omega$-Ti phase during ageing also increases, leading to an increase in the alloy's microhardness.

From the examination of fracture surfaces obtained after tensile testing, one can assess the influence of applied TM processing route on the fracture behaviour of the tested specimens. Figure 8 shows specific images, at different magnifications, of fracture surfaces obtained in the case of as-received (AR) samples (Figure 8a-c) and hot-deformed at $900{ }^{\circ} \mathrm{C}$ (HR) samples (Figure $8 \mathrm{~d}$,e). In the case of AR-state, one can observe that the fracture surface analysis shows a fibrous morphology (Figure 8a) with a higher density of voids and dimples (Figure $8 \mathrm{~b}$ ), indicating a pronounced ductility. The voids coalescence mechanism is observed (Figure $8 \mathrm{c}$ ). Overall, the AR-state shows a ductile behaviour, confirming the observations made during mechanical properties analysis (high strength $-1057 \pm 14 \mathrm{MPa}$ and high elongation to fracture- $12.9 \pm 1.8 \%$ ). The case of HR state shows, beside fibrous areas, the presence of large crevices/fissures and cleavage areas/surfaces (Figure 8d). Within the fibrous areas, one can observe the presence of small voids and shallow dimples, with a decreased density in comparison with the AR state (Figure 8e) and also voids coalescence areas (Figure 8f), indicating boundaries of priorly deformed $\alpha$-Ti/ $\beta$-Ti colonies. Overall, HR state shows a mixed brittle-ductile behaviour, confirming 
the observations made during mechanical properties analysis (high strength $-1012 \pm 11 \mathrm{MPa}$ and low elongation to fracture $-3.2 \pm 0.6 \%$ ).

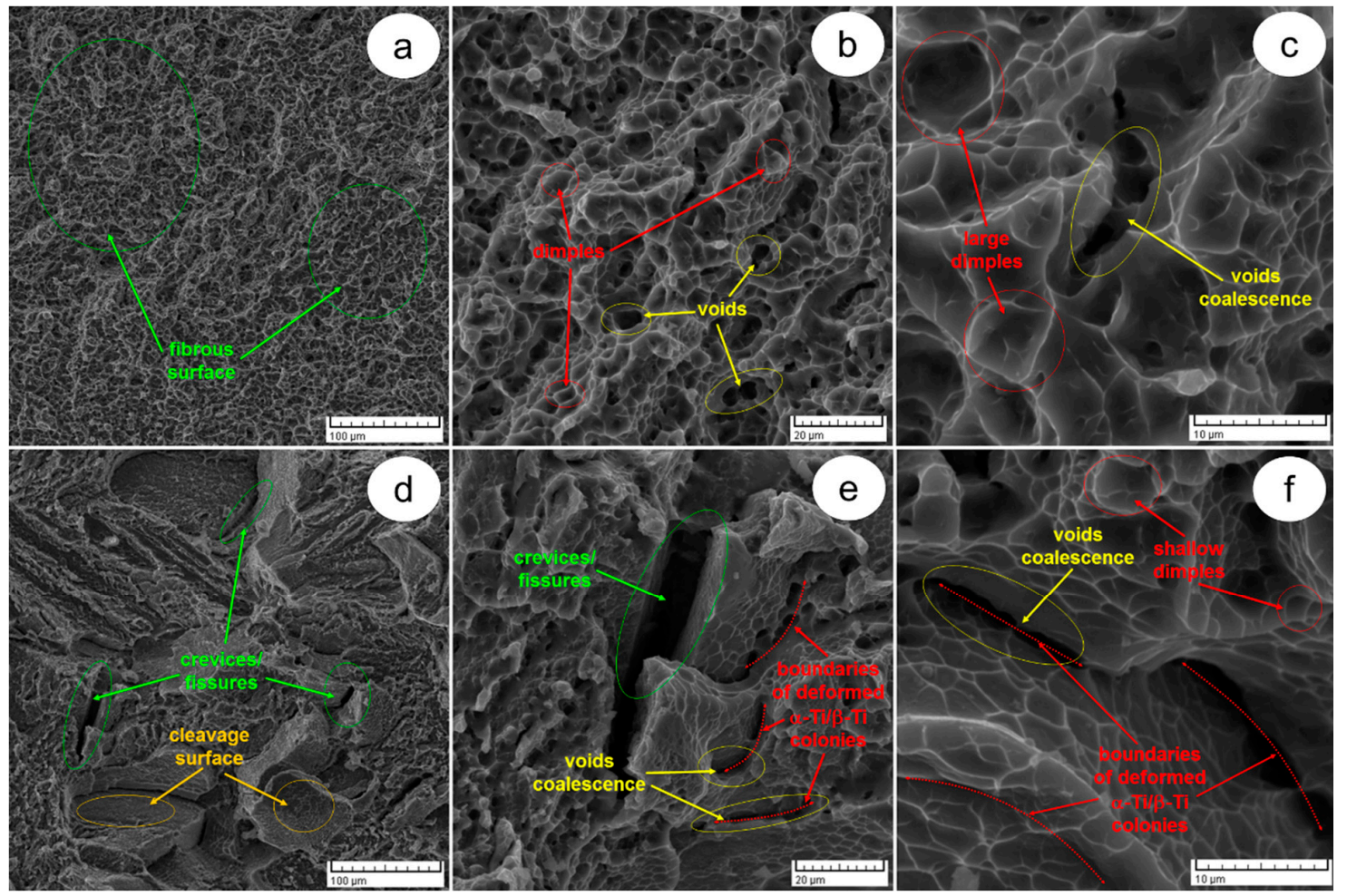

Figure 8. SEM-SE images of fracture surfaces after tensile testing of Ti-6246 alloy $(\mathbf{a}-\mathbf{c})$ in AR state in different magnifications; (d-f) HR state.

Analysing the case of solution treatment performed at $800{ }^{\circ} \mathrm{C}-\mathrm{ST} 1$ state, one can observe that the fracture surfaces are showing the presence of large cleavage surfaces, large crevices/fissures and small fibrous areas (Figure 9a). The fibrous areas show the presence of shallow dimples and small-size voids, indicating a limited ductility. Analysing the size of all morphological aspects (cleavage surfaces, crevices/fissures and fibrous surfaces), one can conclude that the ST1 state shows a typical aspect of a mixed brittle-ductile behaviour. In the case of solution treatment performed at $900{ }^{\circ} \mathrm{C}-\mathrm{ST} 2$ state, one can observe that the fracture surfaces are showing similar morphological aspects with the case of ST1 state, but with larger-size fibrous areas and lower-size cleavage surfaces (Figure 9b). The fibrous areas show the presence of small-size voids, shallow dimples and voids coalescence, confirming the higher ductility (elongation to fracture) obtained in this case, in comparison with the ST1 case. Also, the ST2 state shows a typical aspect of mixed brittle-ductile behaviour. The case of solution treatment performed at $1000{ }^{\circ} \mathrm{C}-\mathrm{ST} 3$ state, shows the presence of large cleavage surface, large crevices/fissures and fibrous areas. In depth analysis of fibrous areas still shows the presence of small-size voids, shallow dimples and signs of voids coalescence (Figure 9c), indicating a higher ductility, in comparison with the ST1 state. Overall, the ST3 state shows a mixed brittle-ductile behaviour, but with a lower/limited ductility in comparison with the ST2 state, confirming all observations made during mechanical properties analysis.

Analysing the case of ageing treatment performed on ST1 solution-treated samples (ST1 + A), one can notice the presence of small-size cleavage surfaces, dimples and voids (Figure 9d). Also, one can notice a higher void density in the case of ST1 + A state, in comparison with the initial ST1 state. Overall, ST1 + A state shows a mixed brittle-ductile mechanical behaviour. The case of ageing treatment performed on ST2 solution-treated samples (ST2 + A) shows an increased density of small-size dimple and voids, indicating an increased ductility, in comparison with the initial ST2 state. Besides voids and 
dimples, one can observe a higher density of small-size cleavage surfaces/facets, indicating induced embrittlement (Figure 9e). The same behaviour is identified in the case of ageing treatment performed on ST3 solution-treated samples (ST3 + A), where one can observe the presence of a higher density of small-size cleavage surfaces/facets, voids, dimples and larger areas where voids coalescence occurred (Figure 9f), indicating a lower ductility comparing with the ST2 + A state. The generation of small-size cleavage surfaces/facets must be related to the presence of brittle $\alpha$-Ti/ $\omega$-Ti phase within the $\beta$-Ti phase [50-52,57-60].

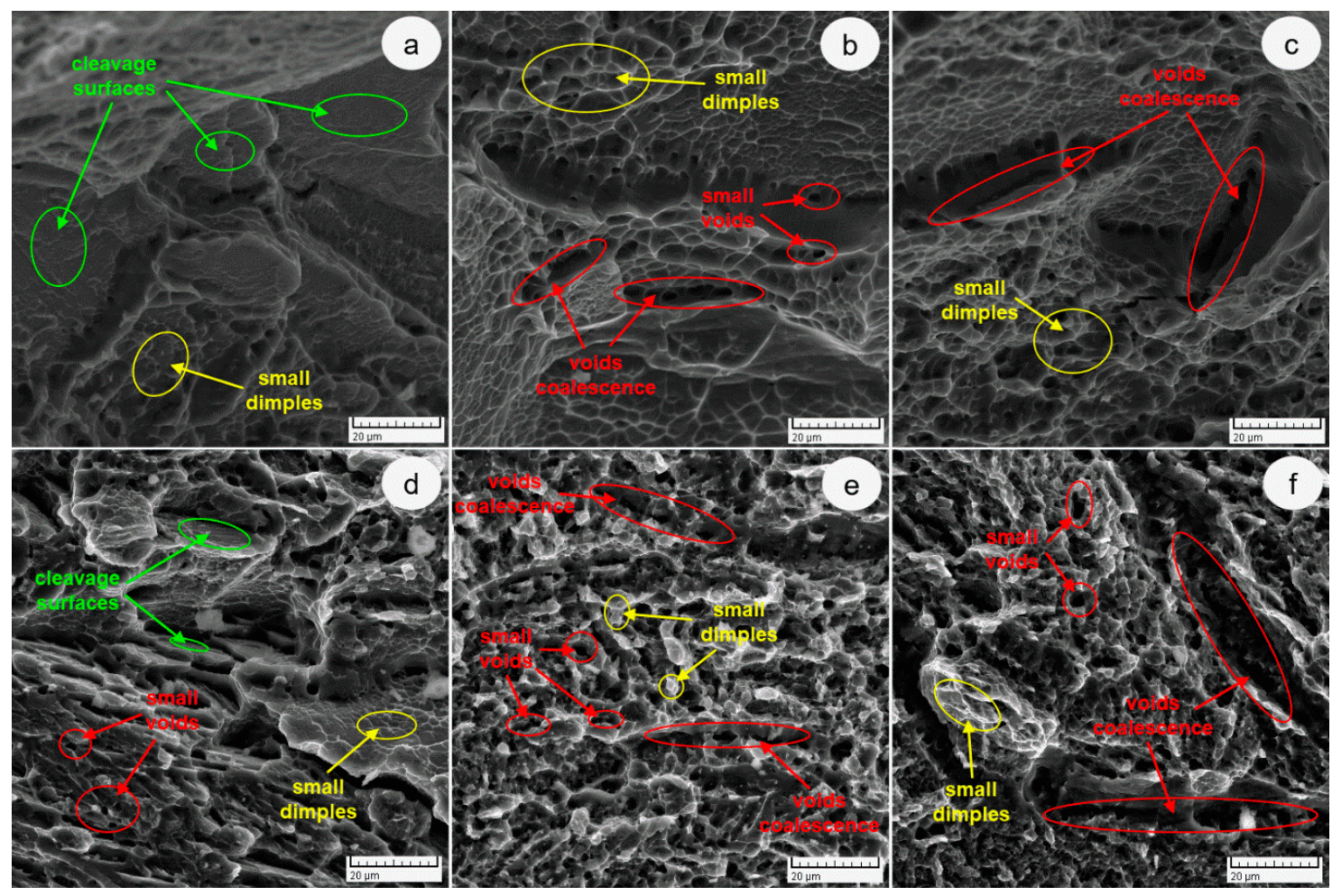

Figure 9. SEM-SE images of fracture surfaces after tensile testing of (a) solution treated at $800{ }^{\circ} \mathrm{C}(\mathrm{ST} 1)$ state; (b) solution treated at $900{ }^{\circ} \mathrm{C}(\mathrm{ST} 2)$ state; (c) solution treated at $1000{ }^{\circ} \mathrm{C}$ (ST3) state; (d) solution treated at $800{ }^{\circ} \mathrm{C}$ and aged at $600{ }^{\circ} \mathrm{C}(\mathrm{ST} 1+\mathrm{A})$ state; (e) solution treated at $900{ }^{\circ} \mathrm{C}$ and aged at $600{ }^{\circ} \mathrm{C}$ $(\mathrm{ST} 2+\mathrm{A})$ state; $(\mathbf{f})$ solution treated at $1000{ }^{\circ} \mathrm{C}$ and aged at $600{ }^{\circ} \mathrm{C}(\mathrm{ST} 3+\mathrm{A})$ state.

\section{Conclusions}

The influence of solution and ageing treatments on the microstructure and mechanical behaviour of a hot deformed Ti-6246 alloy can be summarised as follows:

- $\quad$ The main positive effect of applying solution and ageing treatments is represented by the possibility to control exhibited mechanical behaviour of Ti-6246 alloy;

- A solution treatment temperature below $\beta$-transus induces the formation of $\alpha^{\prime}$-Ti phase, influencing the alloy's mechanical behaviour by increasing both strength and ductility properties in comparison with the hot-deformed state; the Ti-6246 alloy shows the highest strength and ductility when solution treatment is performed close to $\beta$-transus temperature;

- A solution treatment temperature above $\beta$-transus induces the formation of $\alpha^{\prime \prime}$-Ti phase, influencing the alloy's mechanical behaviour by decreasing both strength and ductility properties;

- During ageing treatment $\alpha^{\prime}-\mathrm{Ti} / \alpha^{\prime \prime}-\mathrm{Ti} \rightarrow \alpha-\mathrm{Ti} / \beta-\mathrm{Ti}$ and $\beta-\mathrm{Ti} \rightarrow \alpha-\mathrm{Ti} / \omega$-Ti transformations occur, influencing the alloy's mechanical behaviour by increasing the strength, ductility and microhardness due to the stress relieving and dispersion precipitation strengthening mechanisms. 
Further optimization of the TM processing route, in order to achieve an adequate combination of mechanical properties, high strength properties and increased ductility in Ti-6246 alloy is currently being undertaken by the present authors.

Author Contributions: M.H.I.A. and V.D.C. conceived and designed the experiments; M.H.I.A., E.M.C., A.R., G.C., N.S, and V.D.C. performed the experiments; M.H.I.A., N.S, and V.D.C. analysed the data; A.R. contributed reagents/materials/analysis tools; M.H.I.A., V.D.C. and N.S. reviewed and edited the paper. All authors have read and agreed to the published version of the manuscript.

Funding: This research received no external funding.

Conflicts of Interest: The authors declare no conflict of interest. The founding sponsors had no role in the design of the study; in the collection, analyses, or interpretation of data; in the writing of the manuscript, and in the decision to publish the results.

\section{References}

1. Fanning, J.C.; Boyer, R.R. Properties of TIMETAL 555-A new near-beta titanium alloy for airframe components. In Ti-2003 Science and Technology, Proceedings of the 10th World Conference on Titanium, Hamburg, Germany, 13-18 July 2003; Lütjering, G., Albrecht, J., Eds.; Wiley-VCH: Hamburg, Germany, 2003; Volume IV, pp. 2643-2650.

2. Nyakana, S.L.; Fanning, J.C.; Boyer, R.R. Quick reference guide for $\beta$ titanium alloys in the 00 s. J. Mater. Eng. Perform. 2005, 14, 799-811. [CrossRef]

3. Cotton, J.D.; Boyer, R.R.; Briggs, R.D.; Baggerly, R.G.; Meyer, C.A.; Carter, M.D.; Wood, W.; Tewksbury, G.; Li, V.; Yao, X.; et al. Phase transformations in Ti-5Al-5Mo-5V-3Cr-0.5Fe. In Ti-2007 Science and Technology Proceedings of the 11th World Conference on Titanium, Kyoto, Japan, 3-7 June 2007; Niinomi, M., Akiyama, S., Hagiwara, M., Ikeda, M., Maruyama, K., Eds.; The Japan Institute of Metals: Kyoto, Japan, 2007; Volume I, pp. 471-474.

4. Banerjee, D.; Williams, J.C. Perspectives on titanium science and technology. Acta Mater. 2013, 61, 844-879. [CrossRef]

5. Manda, P.; Ghosal, P.; Chakkingal, U.; Singh, A.K. Effect of alloying elements in hot-rolled metastable $\beta$-titanium alloys: Part I. evolution of microstructure and texture. Metall. Mater. Trans. A 2015, 46, $2646-2663$. [CrossRef]

6. Ma, Y.; Du, Z.; Cui, X.; Cheng, J.; Liu, G.; Gong, T.; Liu, H.; Wang, X.; Chen, Y. Effect of cold rolling process on microstructure and mechanical properties of high strength $\beta$ titanium alloy thin sheets. Prog. Nat. Sci. Mater. Int. 2018, 28, 711-717. [CrossRef]

7. Zhang, L.C.; Chen, L.Y.; Wang, L. Surface modification of titanium and titanium alloys: Technologies, developments, and future interests. Adv. Eng. Mater. 2020, 22, 1901258. [CrossRef]

8. Froes, F.H. Titanium: Physical Metallurgy, Processing and Applications, 1st ed.; ASM International: Cleveland, OH, USA, 2015; p. 417.

9. Polmear, I.; StJohn, D.; Nie, J.-F.; Qian, M. Light Alloys: Metallurgy of the Light Metals, 5th ed.; Matthew Deans: Oxford, UK, 2017; p. 533.

10. Liu, S.; Liu, J.; Wang, L.; Ma, R.L.W.; Zhong, Y.; Lu, W.; Zhang, L.C. Superelastic behavior of in-situ eutectic-reaction manufactured high strength 3D porous NiTi-Nb scaffold. Scr. Mater. 2020, 181, 121-126. [CrossRef]

11. Boyer, R.R. An overview on the use of titanium in the aerospace industry. Mater. Sci. Eng. A 1996, 213, 103-114. [CrossRef]

12. Ready, A.J.; Haynes, P.D.; Grabowski, B.; Rugg, D.; Sutton, A.P. The role of molybdenum in suppressing cold dwell fatigue in titanium alloys. Proc. R. Soc. A Maths. Phys. Eng. Sci. 2017, 473, 1-15. [CrossRef]

13. Froes, F.H.; Highberger, W.T. Synthesis of corona 5 (Ti-4.5 Al-5Mo-1.5Cr). JOM 1980, 32, 57-64. [CrossRef]

14. Weiss, I.; Froes, F.H.; Eylon, D.; Welsch, G.E. Modification of alpha morphology in Ti-6Al-4V by thermomechanical processing. Metall. Mater. Trans. A 1986, 17, 1935-1947. [CrossRef]

15. Gupta, A.; Khatirkar, R.K.; Kumar, A.; Parihar, M.S. Investigations on the effect of heating temperature and cooling rate on evolution of microstructure in an $\alpha+\beta$ titanium alloy. Mater. Res. Soc. 2018, 33, 946-957. [CrossRef] 
16. Dabrowski, R. The kinetics of phase transformations during continuous cooling of the Ti6Al4V alloy from the singlephase $\beta$ range. Arch. Metall. Mater. 2011, 56, 703-707. [CrossRef]

17. Xu, J.; Zeng, W.; Zhao, Y.; Sun, X.; Du, Z. Influence of cooling rate following heat treatment on microstructure and phase transformation for a two-phase alloy. J. Alloy. Compd. 2016, 688, A301-A309. [CrossRef]

18. Lütjering, G.; Williams, J.C. Titanium, 2nd ed.; Springer: Berlin/Heidelberg, Germany, 2007; p. 449.

19. Zhang, J.; Tasan, C.C.; Lai, M.J.; Dippel, A.-C.; Raabe, D. Complexion-mediated martensitic phase transformation in titanium. Nat. Commun. 2017, 8, 1-8. [CrossRef] [PubMed]

20. Duerig, T.W.; Terlinde, G.T.; Williams, J.C. Phase transformations and tensile properties of Ti-10V-2Fe-3Al. Metall. Mater. Trans. A 1980, 11, 1987-1998. [CrossRef]

21. Menon, E.S.K.; Chakravartty, J.K.; Wadekar, S.L.; Banerjee, S. Stress induced martensitic transformation in Ti-20V. J. Phys. Colloq. 1982, 43, C321-C326. [CrossRef]

22. Ninomi, M.; Kobayashi, T.; Inagaki, I.; Thompson, A.W. The effect of deformation-induced transformation on the fracture toughness of commercial titanium alloys. Metall. Mater. Trans. A 1990, 21, 1733-1744. [CrossRef]

23. Ishiyama, S.; Hanada, S.; Izumi, O. Effect of $\mathrm{Zr}$, Sn and $\mathrm{Al}$ additions on deformation mode and beta phase stability of metastable beta Ti alloys. ISIJ Int. 1991, 31, 807-813. [CrossRef]

24. Kim, H.Y.; Miyazaki, S. Ni-Free Ti-Based Shape Memory Alloys, 1st ed.; Butterworth-Heinemann: Oxford, UK, 2018; pp. 1-52.

25. He, J.; Li, D.; Jiang, W.; Ke, L.; Qin, G.; Ye, Y.; Qin, Q.; Qiu, D. The martensitic transformation and mechanical properties of Ti6Al4V prepared via selective laser melting. Materials 2019, 12, 321. [CrossRef]

26. Donachie, M.J. Titanium: A Technical Guide, 2nd ed.; ASM International: Cleveland, OH, USA, $2000 ;$ p. 216.

27. El-Hadad, S.; Nady, M.; Khalifa, W.; Shash, A. Influence of heat treatment conditions on the mechanical properties of Ti-6Al-4V alloy. Can. Metall. Q. 2018, 57, 186-193. [CrossRef]

28. ASM International Handbook Committee. Properties and Selection: Nonferrous Alloys and Special-Purpose Materials, 10th ed.; ASM International: Cleveland, OH, USA, 1992; p. 3470.

29. El-Hadad, S.; Mhaede, M.; Ibrahiem, K.M. Microstructural effects on corrosion behavior of investment cast Ti-6.5Al-3.4Mo-1.7Zr alloy. Int. J. Cast Met. Res. 2016, 29, 243-250. [CrossRef]

30. Kolli, R.P.; Devaraj, A. A review of metastable beta titanium alloys. Metals 2018, 8, 506. [CrossRef]

31. TIMETAL 6-2-4-6 Data Sheet. Available online: https://www.timet.com/assets/local/documents/datasheets/ alphaandbetaalloys/6246.pdf (accessed on 9 July 2020).

32. Zhang, X.D.; Evans, D.J.; Baeslack, W.A.; Fraser, H.L. Effect of long term aging on the microstructural stability and mechanical properties of Ti-6Al-2Cr-2Mo-2Sn-2Zr alloy. Mater. Sci. Eng. A 2003, 344, 300-311. [CrossRef]

33. Wu, C.; Zhan, M. Microstructural evolution, mechanical properties and fracture toughness of near $\beta$ titanium alloy during different solution plus aging heat treatments. J. Alloy. Compd. 2019, 805, 1144-1160. [CrossRef]

34. Shekhar, S.; Sarkar, R.; Kar, S.K.; Bhattacharjee, A. Effect of solution treatment and aging on microstructure and tensile properties of high strength $\beta$ titanium alloy Ti-5Al-5V-5Mo-3Cr. Mater. Des. 2015, 66, 596-610. [CrossRef]

35. Jia, W.J.; Zeng, W.D.; Yu, H.Q. Effect of aging on the tensile properties and microstructures of a near-alpha titanium alloy. Mater. Des. 2014, 58, 108-115. [CrossRef]

36. Du, Z.; Xiao, S.; Xu, L.; Tian, J.; Kong, F.; Chen, Y. Effect of heat treatment on microstructure and mechanical properties of a new high strength titanium alloy. Mater. Des. 2014, 55, 183-190. [CrossRef]

37. Semiatin, S.L.; Seetharaman, V.; Weiss, I. The thermomechanical processing of alpha/beta titanium alloys. JOM 1997, 49, 33-39. [CrossRef]

38. Weiss, I.; Semiatin, S.L. Thermomechanical processing of alpha titanium alloys-An overview. Mater. Sci. Eng. A 1999, 263, 243-256. [CrossRef]

39. Semiatin, S.L.; Knisley, S.L.; Fagin, P.N.; Barker, D.R.; Zhang, F. Microstructure evolution during alpha-beta heat treatment of Ti-6Al-4V. Metall. Mater. Trans. A 2003, 34, 2377-2386. [CrossRef]

40. Dabrowski, R. The kinetics of phase transformations during continuous cooling of Ti-6Al-4V alloy from the diphase $\alpha+\beta$ range. Arch. Metall. Mater. 2011, 56, 217-221.

41. Krakhmalev, P.; Fredriksson, G.; Yadroitsava, I.; Kazantseva, N.; Du Plessis, A.; Yadroitsev, I. Deformation behavior and microstructure of Ti6Al4V manufactured by SLM. Phys. Procedia 2016, 83, 778-788. [CrossRef]

42. Liu, J.; To, A.C. Quantitative texture prediction of epitaxial columnar grains in additive manufacturing using selective laser melting. Addit. Manuf. 2017, 16, 58-64. [CrossRef] 
43. Mantri, S.A.; Banerjee, R. Microstructure and micro-texture evolution of additively manufactured $\beta$-Ti alloys. Addit. Manuf. 2018, 23, 86-98. [CrossRef]

44. Yamanaka, K.; Saito, W.; Mori, M.; Matsumoto, H.; Chiba, A. Preparation of weak-textured commercially pure titanium by electron beam melting. Addit. Manuf. 2015, 8, 105-109. [CrossRef]

45. Ji, X.; Gutierrez-Urrutia, I.; Emura, S.; Liu, T.; Hara, T.; Min, X.; Ping, D.; Tsuchiya, K. Twinning behavior of orthorhombic- $\alpha$ martensite in a Ti-7.5Mo alloy. Sci. Technol. Adv. Mater. 2019, 20, 401-411. [CrossRef]

46. Hafeez, N.; Liu, J.; Wang, L.; Wei, D.; Tang, Y.; Lu, W.; Zhang, L.C. Superelastic response of low-modulus porous beta-type Ti-35Nb-2Ta-3Zr alloy fabricated by laser powder bed fusion. Addit. Manuf. 2020, 34, 101264. [CrossRef]

47. Chong, Y.; Deng, G.; Gao, S.; Yi, J.; Shibata, A.; Tsuji, N. Yielding nature and Hall-Petch relationships in Ti-6Al-4V alloy with fully equiaxed and bimodal microstructures. Scr. Mater. 2019, 172, 77-82. [CrossRef]

48. Yu, Y.; Hui, S.; Ye, W.; Xiong, B. Mechanical properties and microstructure of an $\alpha+\beta$ titanium alloy with high strength and fracture toughness. Rare Met. 2009, 28, 346-349. [CrossRef]

49. Padmalatha, T.S.R.V.; Chakkingal, U. The effect of heat treatment and the volume fraction of the alpha phase on the workability of Ti-5Al-5Mo-5V-3Cr alloy. J. Mater. Eng. Perform. 2019, 28, 5352-5360. [CrossRef]

50. Guo, Y.; Jung, T.; Chiu, Y.L.; Li, H.; Bray, S.; Bowen, P. Microstructure and microhardness of Ti6246 linear friction weld. Mater. Sci. Eng. A 2013, 562, 17-24. [CrossRef]

51. Chamanfar, A.; Pasang, T.; Ventura, A.; Misiolek, W.Z. Mechanical properties and microstructure of laser welded Ti-6Al-2Sn-4Zr-2Mo (Ti6242) titanium alloy. Mater. Sci. Eng. A 2016, 663, 213-224. [CrossRef]

52. Xu, P.; Zhou, L.; Han, M.; Wei, Z.; Liang, Y. Flash-butt welded Ti6242 joints preserved base-material strength and ductility. Mater. Sci. Eng. A 2020, 774, 138915. [CrossRef]

53. Tang, B.; Chu, Y.; Zhang, M.; Meng, C.; Fan, J.; Kou, H.; Li, J. The $\omega$ phase transformation during the low temperature aging and low rate heating process of metastable $\beta$ titanium alloys. Mater. Chem. Phys. 2020, 239, 122-125. [CrossRef]

54. Ali, T.; Wang, L.; Cheng, X.; Liu, A.; Xu, X. Omega phase formation and deformation mechanism in heat treated Ti-5553 alloy under high strain rate compression. Mater. Lett. 2019, 236, 163-166. [CrossRef]

55. Jones, N.G.; Dashwood, R.J.; Jackson, M.; Dye, D. Beta phase decomposition in Ti-5Al-5Mo-5V-3Cr. Acta Mater. 2009, 57, 3830-3839. [CrossRef]

56. Li, M.J.; Min, X.H.; Yao, K.; Ye, F. Novel insight into the formation of alpha-martensite and omega-phase with cluster structure in metastable Ti-Mo alloys. Acta Mater. 2019, 164, 322-333. [CrossRef]

57. Chen, W.; Cao, S.; Kou, W.J.; Zhang, J.Y.; Wang, Y.; Zha, Y.; Pan, Y.; Hu, Q.M.; Sun, Q.Y.; Sun, J. Origin of the ductile-to-brittle transition of metastable beta-titanium alloys: Self-hardening of omega-precipitates. Acta Mater. 2019, 170, 187-204. [CrossRef]

58. Nag, S.; Banerjee, R.; Srinivasan, R.; Hwang, J.Y.; Harper, M.; Fraser, H.L. Omega-assisted nucleation and growth of alpha precipitates in the Ti-5Al-5Mo-5V-3Cr-0.5Fe beta titanium alloy. Acta Mater. 2009, 57, 2136-2147. [CrossRef]

59. Shi, R.; Zheng, Y.; Banerjee, R.; Fraser, H.L.; Wang, Y. $\omega$-Assisted $\alpha$ nucleation in a metastable $\beta$ titanium alloy. Scr. Mater. 2019, 171, 62-66. [CrossRef]

60. Gao, J.; Knowles, A.J.; Guan, D.; Rainforth, W.M. $\omega$ phase strengthened 1.2 GPa metastable $\beta$ titanium alloy with high ductility. Scr. Mater. 2019, 162, 77-81. [CrossRef]

(C) 2020 by the authors. Licensee MDPI, Basel, Switzerland. This article is an open access article distributed under the terms and conditions of the Creative Commons Attribution (CC BY) license (http://creativecommons.org/licenses/by/4.0/). 